\title{
Análise dos modelos didáticos pessoais apresentados por um grupo de licenciandos em Química
}

\author{
Analyses of the personal didactic models presented \\ by a group of teachers training to teach Chemistry
}

João Batista Santos Junior ${ }^{1}$ • Fernanda Keila Marinho da Silva ${ }^{1}$

\begin{abstract}
Resumo: O objetivo do artigo é apresentar e discutir a influência das disciplinas pedagógicas na formação profissional de um grupo de licenciandos do curso de Química de uma universidade federal do estado de São Paulo. Para isso, utilizou-se um instrumento baseado nos modelos didáticos propostos por García Pérez nos anos 2000. Os resultados permitiram a identificação dos modelos didáticos desses alunos e indicaram que alunos que cursaram maior número de disciplinas de natureza didático-pedagógicas apresentaram modelos didáticos pessoais mais organizados e consistentes. Essa análise corrobora com resultados de outros estudos que apontam para a necessidade de articulação das disciplinas científicas com as pedagógicas e possibilitam lançar inferências sobre a construção da grade curricular e o próprio desenho do curso de formação de professores.
\end{abstract}

Palavras-chave: Modelos didáticos. Formação inicial de professores. Ensino de química. Ensino superior.

\begin{abstract}
The aim of this article was to present and to discuss the influence of the pedagogical courses in the teacher training of a group of Chemistry graduate students of a federal university in São Paulo State. For that, a methodology based on didactic models by García Pérez in the 2000s was used. The results allowed the identification of the didactic models of these students and they indicated that students who attended a larger number of pedagogical courses presented didactic models that were more organized and coherent. This analysis confirms the results of other articles which point to the need of an articulation between scientific and pedagogical courses, and it allows some suggestions for the university program and the teacher training course structure.
\end{abstract}

Keywords: Didactic models. Initial training of Chemistry teacher. Chemistry teaching. Higher education.

\footnotetext{
${ }^{1}$ Universidade Federal de São Carlos (UFSCar), Centro de Ciências, Tecnologia e Sustentabilidade, Departamento de Física, Química e Matemática, Sorocaba, SP, Brasil. E-mail: <joaobats@ufscar.br>.
} 


\section{Introdução}

As licenciaturas vêm se configurando como objeto de investigação de um grande número de pesquisadores. André (2009), por exemplo, mostra que no período de 1990 a 2000 houve aumento na produção da área de pesquisa em formação de professores. A formação inicial foi um dos objetos do estudo supracitado e indica que a produção teria passado de 34 teses e dissertações em 1999, para 63 em 2003.

A ampliação do interesse pelos acadêmicos denotou, progressivamente, a riqueza desse campo de investigação. Nesse sentido, apresentou um cenário repleto de questões a serem investigadas visando melhoria e discussão dos processos formativos. Aspectos que parecem ter chamado a atenção dos pesquisadores são: a desarticulação entre as disciplinas pedagógicas com as específicas, a influência de uma visão tecnicista da formação, pouca ênfase na reflexão e valorização da prática. Especificamente no caso da formação de professores na área das ciências da natureza, as pesquisas indicaram a problemática da organização curricular típica do bacharelado e a visão positivista oriunda das áreas científicas. Elementos complexos e que colaboram com a desvalorização da formação mais ampla e crítica dos futuros professores. O resultado desse cenário quase sempre é um futuro professor despreparado para atuar em consonância com os pressupostos difundidos pela pesquisa em ensino.

No ano de 2015 foram homologadas as Diretrizes Curriculares Nacionais para a formação inicial e continuada em nível superior (BRASIL, 2015). Esse documento possui ação norteadora e normativa para os cursos de licenciatura, a exemplo dos documentos que a antecedem cronologicamente. A sua importância e sua abrangência nacional o caracterizam como um documento que deve ser discutido pelos docentes nas instituições de ensino superior, tanto para que esses docentes conheçam o próprio documento e o incorporem na concepção formativa dos seus respectivos cursos e disciplinas, mas, sobretudo pelo impacto direto na organização curricular desses cursos mostrando o "alinhavo" paulatino e progressivo entre políticas e práticas. Fugiria ao escopo do presente artigo debater em profundidade as diretrizes (para isso, veja recente publicação de DOURADO, 2015). O intuito é apontar como a formação de professores se constitui em um tema que, apesar de debatido há muito tempo, ainda demonstra o potencial para a continuidade de indagações e sistematizações que podem e devem incidir na formação que projetamos em nossas disciplinas.

Estudos recentes (PAGANINI, 2012; SANT'ANNA; MATTOS; COSTA, 2015) indicam que a formação inicial permanece aquém das necessidades formativas dos egressos que estão iniciando suas atividades profissionais na escola. A análise de alguns elementos presentes nesses textos aponta para dois aspectos que, embora já venham sendo há muito tempo discutidos pela pesquisa na área (ABIB, 2002; GRIGOLI et al., 2010), continuam sendo problemáticos para as instituições formadoras: a desarticulação entre as disciplinas específicas com as didático-pedagógicas e a pouca ou nula valorização da escola como lócus de formação docente.

O estágio supervisionado, que em tese poderia fazer a interação entre a formação dos licenciandos com os dois aspectos apontados, nem sempre atinge esse objetivo. As principais críticas ao estágio incidem na organização curricular das licenciaturas que concebem o estágio como um conjunto de disciplinas práticas ofertadas no final do curso depois das disciplinas teóricas, o que desfavorece a articulação entre ambas (MIZUKAMI et al., 2002). Raymundo (2014) aponta para dificuldades como a falta de fundamentação teórica dos estagiários na exe- 
cução do estágio, a falta de integração entre a universidade e a escola e até mesmo, a falta de acompanhamento dos professores orientadores dos estágios.

Vale ressaltar que algumas ações que visam melhorar a formação inicial dos futuros docentes foram propostas nos últimos anos. Entre essas, tem destaque o Programa Institucional de Bolsas de Iniciação à Docência (PIBID). Desde seu primeiro edital o PIBID atingiu milhares de licenciandos em todo o país articulando escolas com as instituições formadoras em todas as regiões brasileiras. Infelizmente, a atual conjuntura econômica do país induz o PIBID a cortes orçamentários severos. Além disso, sua própria estrutura e dinâmica de funcionamento encontram-se em debate.

O recorte colocado no presente artigo relaciona-se ao impacto e à importância das disciplinas pedagógicas na formação do licenciando. A partir dessa discussão, espera-se propiciar uma reflexão acerca da articulação dessas disciplinas com as demais disciplinas das licenciaturas. Embora se reconheça a complexidade dessa iniciativa reconhece-se que a mesma seja fundamentalmente importante para uma formação mais abrangente e potencialmente problematizadora. Dentro desse contexto, o objetivo principal do artigo é apresentar um panorama dos modelos didáticos de estudantes de licenciatura em química, identificando indícios de como as disciplinas pedagógicas podem organizar as ideias gerais sobre o fazer pedagógico.

A discussão proposta será realizada utilizando-se dos modelos didáticos descritos por García Pérez (2000). Ele representa um instrumento bastante sistematizado que colabora sobremaneira para categorizar e propor reflexão sobre o fazer pedagógico. Pretende-se que esse artigo represente um convite para que nós, formadores de professores e professores de disciplinas que integram a formação profissional, possamos refletir sobre o impacto do que vimos desenvolvendo.

\section{Os modelos didáticos e sua importância no trabalho junto às licenciaturas}

A ideia de modelo didático tem sido utilizada como uma tentativa de representar os fazeres pedagógicos dos professores (GARCÍA PÉREZ, 2000; PORLÁN ARIZA; RIVERO GARCÍA; MARTÍN DEL POZO, 1997, 1998). As tomadas de decisões, nem sempre conscientes, que permeiam o fazer pedagógico de um professor estão impregnadas por suas crenças e saberes tácitos (GIL-PÉREZ; CARVALHO, 1992). Esse fazer pedagógico é o que se denomina modelo didático do professor. $\mathrm{O}$ modelo didático é um esquema mediador entre a realidade e o pensamento do professor, uma estrutura na qual se organiza o conhecimento. Terá sempre um caráter provisório e de aproximação com uma realidade, além de ser um recurso para o desenvolvimento e fundamentação para a prática do professor. (CHROBAK; BENEGAS, 2006).

A ideia de modelo didático permite abordar (de maneira simplificada, como qualquer modelo) a complexidade da realidade escolar, ao mesmo tempo em que ajuda a propor procedimentos de intervenção e a fundamentar, portanto, linhas de investigação educativa e de formação dos professores (GARCÍA PÉREZ, 2000). Porlán Ariza, Rivero García e Martín del Pozo (1997) utilizam o termo "concepções epistemológicas do professor" com um significado muito próximo ao de "modelo didático", ou seja, um conjunto de ideias e formas de atuação que se relacionam com o conhecimento escolar, o seu processo de construção, ideias essas que podem se manifestar de maneira implícita ou não. 
Segundo García Pérez (2000), um modelo didático é constituído pelas crenças, pela cultura, pelas relações sociais que permeiam o processo de ensino-aprendizagem e a intencionalidade do professor em ensinar os alunos. A construção desses modelos está baseada em cinco dimensões didáticas: Qual é o objetivo do ensino? O que deve ser ensinado ao aluno? Qual é a relevância das ideias e interesses do aluno? Como ensinar? Como avaliar? De acordo com essas dimensões, o pesquisador propõe quatro modelos didáticos: o tradicional, o tecnológico, o espontaneísta e o alternativo.

No modelo tradicional, baseado em concepções advindas de uma perspectiva da transmissão cultural, há uma supervalorização dos conteúdos, os alunos são avaliados em relação à assimilação desses conteúdos de maneira individualizada, o papel do aluno no processo é passivo, ou seja, cabe a ele acatar e fazer o que o professor determina, não tendo maior contribuição no planejamento de atividades. Ao docente cabe, além do planejamento, controlar a disciplina da sala.

O modelo tecnológico seria uma espécie de modernização do modelo tradicional, sendo caracterizado pela incorporação de conteúdos ditos mais modernos vinculados a temáticas sociais e ambientais, pela valorização de objetivos e metas traçados no planejamento feito pelo professor. As concepções dos alunos, quando consideradas no processo, são vistas como erros conceituais, o papel do aluno é o de executar todas as atividades programadas pelo professor, que nesse modelo tem função de direcionar o andamento das atividades programadas.

O modelo espontaneísta pode ser visto como um contraponto ao modelo tradicional, pois o aluno é tido como foco do processo, sendo valorizado o desenvolvimento de habilidades e competências. Os interesses do aluno são um componente fundamental nesse modelo didático, pois é a partir deles, juntamente com a realidade na qual estão inseridos, que o professor elabora seu planejamento. Os alunos têm papel ativo, sendo esperado que eles sejam capazes de aprender determinados conteúdos por descoberta e compreender o contexto social em que vivem. O professor não tem papel gerencial do processo, sendo visto como uma liderança que coordena o trabalho dos alunos.

E, finalmente, o modelo alternativo, que representa um ensino em que o aluno vai aos poucos aumentando seus conhecimentos e, consequentemente, podendo atuar no mundo que o rodeia. Tanto o professor quanto o aluno exercem um papel ativo, os primeiros como investigadores de suas práticas pedagógicas e os segundos como construtores e reconstrutores de suas aprendizagens, que são alcançadas pela implantação de situações-problema que exigem do aluno posturas investigativas para a sua resolução. As ideias e interesses dos alunos são considerados nesse modelo didático. Uma síntese das características de cada modelo, a partir das dimensões já apresentadas é exposta no Quadro 1.

Os modelos didáticos são bastante flexíveis quanto à aplicação. Isso significa que as dimensões podem ser dirigidas para diferentes públicos que vivenciam, já vivenciaram ou que ainda vivenciarão a experiência docente. E é possível inferir que o tempo de vivência e as diferentes experiências conduzem a composição dos modelos de maneira notadamente diferente.

Para André (2009), apesar de as disciplinas específicas e pedagógicas dos cursos de formação inicial terem sido alvo de grande número de trabalhos na década de 1990, faltaram estudos que investigassem as articulações entre elas. É reconhecida a pouca expressão interativa entre professores de disciplinas específicas com as pedagógicas. Mas é também pouco investigada a potencialidade da relação entre essas disciplinas na construção do "fazer pedagógico". 
Quadro 1. Características dos modelos didáticos

\begin{tabular}{|c|c|c|c|c|}
\hline Dimensão didática & Tradicional & Tecnológico & Espontaneísta & Alternativo \\
\hline $\begin{array}{l}\text { (1) Qual o objetivo do } \\
\text { ensino? }\end{array}$ & $\begin{array}{l}\text { Transmitir } \\
\text { ao aluno } \\
\text { conteúdos já } \\
\text { consagrados } \\
\text { da cultura } \\
\text { vigente. }\end{array}$ & $\begin{array}{l}\text { Proporcionar } \\
\text { ao aluno uma } \\
\text { formação } \\
\text { moderna e } \\
\text { eficiente. }\end{array}$ & $\begin{array}{l}\text { Capacitar o aluno } \\
\text { para que possa } \\
\text { compreender sua } \\
\text { realidade. }\end{array}$ & $\begin{array}{l}\text { Proporcionar } \\
\text { ao aluno uma } \\
\text { compreensão cada } \\
\text { vez mais complexa } \\
\text { do mundo e de } \\
\text { como atuar nesse. }\end{array}$ \\
\hline $\begin{array}{l}\text { (2) O que deve ser } \\
\text { ensinado ao aluno? }\end{array}$ & $\begin{array}{l}\text { Conteúdos } \\
\text { disciplinares, } \\
\text { conceitos } \\
\text { específicos. }\end{array}$ & $\begin{array}{l}\text { Conteúdos } \\
\text { que propiciem } \\
\text { uma formação } \\
\text { cultural atual, } \\
\text { conhecimentos } \\
\text { não somente } \\
\text { disciplinares. } \\
\end{array}$ & $\begin{array}{l}\text { Conteúdos } \\
\text { presentes na } \\
\text { realidade imediata } \\
\text { do aluno. }\end{array}$ & $\begin{array}{l}\text { Conhecimentos } \\
\text { interdisciplinares, } \\
\text { o enfoque está no } \\
\text { contexto social. }\end{array}$ \\
\hline $\begin{array}{l}\text { (3) Qual é a relevância } \\
\text { das ideias e interesses } \\
\text { do aluno? }\end{array}$ & $\begin{array}{l}\text { Não } \\
\text { considera. }\end{array}$ & $\begin{array}{l}\text { Quando } \\
\text { considera as } \\
\text { concepções, } \\
\text { essas são vistas } \\
\text { como erros } \\
\text { conceituais. } \\
\end{array}$ & $\begin{array}{l}\text { Considera apenas } \\
\text { os interesses } \\
\text { imediatos do aluno. }\end{array}$ & $\begin{array}{l}\text { Considera os } \\
\text { interesses e as } \\
\text { concepções do } \\
\text { aluno. }\end{array}$ \\
\hline (4) Como ensinar? & $\begin{array}{l}\text { Metodologia } \\
\text { baseada na } \\
\text { transmissão } \\
\text { cultural. }\end{array}$ & $\begin{array}{l}\text { Metodologia } \\
\text { baseada na } \\
\text { transmissão } \\
\text { cultural e } \\
\text { descoberta } \\
\text { dirigida. } \\
\end{array}$ & $\begin{array}{l}\text { Metodologia } \\
\text { baseada no } \\
\text { protagonismo } \\
\text { do aluno, que vai } \\
\text { descobrindo o } \\
\text { conhecimento. }\end{array}$ & $\begin{array}{l}\text { Baseada na ideia da } \\
\text { investigação escolar, } \\
\text { o aluno constrói } \\
\text { e reconstrói o } \\
\text { conhecimento. }\end{array}$ \\
\hline (5) Como avaliar? & $\begin{array}{l}\text { Avaliação } \\
\text { centrada nos } \\
\text { conteúdos } \\
\text { transmitidos, } \\
\text { realizada } \\
\text { por meio } \\
\text { de provas } \\
\text { formais. }\end{array}$ & $\begin{array}{l}\text { Avaliação } \\
\text { centrada nos } \\
\text { conteúdos } \\
\text { transmitidos, } \\
\text { porém em alguns } \\
\text { momentos, pode } \\
\text { aferir o processo. }\end{array}$ & $\begin{array}{l}\text { Avaliação centrada } \\
\text { nas habilidades } \\
\text { e competências; } \\
\text { utiliza a observação } \\
\text { e a produção } \\
\text { individual e } \\
\text { coletiva do aluno. }\end{array}$ & $\begin{array}{l}\text { Avaliação } \\
\text { centrada no } \\
\text { desenvolvimento do } \\
\text { aluno e na atuação } \\
\text { do professor; } \\
\text { utiliza múltiplos } \\
\text { instrumentos } \\
\text { individuais e } \\
\text { coletivos. }\end{array}$ \\
\hline
\end{tabular}

Fonte: García Pérez (2000).

\section{Metodologia}

Os participantes dessa investigação foram 51 alunos de um curso de Química de uma universidade pública federal do Estado de São Paulo. Os licenciandos cursavam o $1^{\circ}, 3^{\circ}, 5^{\circ}$, $7^{\circ}$ e $9^{\circ}$ semestres. A coleta dos dados ocorreu no ano de 2014. Foi solicitado aos alunos que respondessem a um instrumento cujo objetivo era a identificação dos modelos didáticos pes- 
soais dos licenciandos. O instrumento se baseia nas ideias de García Pérez (2000) e consiste de cinco perguntas-chave com características dos modelos didáticos propostos e correspondentes com as dimensões didáticas. O respondente deveria indicar se concordava ou discordava das características e havia a possibilidade de concordar com mais de uma dessas para uma dada pergunta-chave. Com base nas declarações dos licenciandos foi possível identificar os seus respectivos modelos didáticos.

O tratamento dos dados envolveu a organização dos instrumentos respondidos em grupos de acordo com o semestre em que os licenciandos estavam matriculados. Para identificá -los foram atribuídos o rótulo $\mathbf{A x S}$, no qual $\mathbf{A x}$ identifica o aluno e $\mathbf{S}$ o semestre correspondente ao seu estágio no curso, por exemplo, A25 se refere ao aluno 2 do $5^{\circ}$ semestre.

O Quadro 2 sintetiza a sistematização adotada aqui para representar os modelos didáticos pessoais dos licenciandos. Os modelos didáticos tradicional $(\mathrm{T})$, tecnológico $(\mathrm{C})$, espontaneísta (E) e alternativo (A) correspondem aos modelos básicos propostos por García Pérez (2000).

Quadro 2. Sistematização dos modelos didáticos

\begin{tabular}{|c|l|l|c|}
\hline Representação adotada & Modelo didático & Orientação pedagógica & Consistência \\
\hline T & Tradicional & Tradicional & Sim \\
\hline C & Tecnológico & Tradicional & Sim \\
\hline E & Espontaneísta & Construtivista & Sim \\
\hline A & Alternativo & Construtivista & Sim \\
\hline
\end{tabular}

Fonte: García Pérez (2000).

Quando um licenciando declarava aceitar as características de mais de um dos quatro modelos didáticos propostos por García Pérez (2000) para uma mesma pergunta-chave considerou-se que, nesse caso, havia um modelo didático híbrido (SANTOS JR.; MARCONDES, 2010) ou eclético (GUIMARÃES; ECHEVERRÍA; MORAES, 2006). O Quadro 3 apresenta esses modelos híbridos destacados pelos autores citados.

Para representar os modelos didáticos pessoais identificados nessa investigação foi criada uma sistematização que visou explicitar o modelo didático, a sua orientação pedagógica e a consistência das características que o constituem. Essas informações são fundamentais, pois revelam aspectos importantes que estruturam as concepções e o próprio pensamento docente. 
Quadro 3. Modelos didáticos híbridos

\begin{tabular}{|c|c|c|c|}
\hline Representação adotada & Modelo didático & Orientação pedagógica & Consistência \\
\hline $\mathrm{T}$ & Tradicional & Tradicional & Sim \\
\hline $\mathrm{C}$ & Tecnológico & Tradicional & $\operatorname{Sim}$ \\
\hline $\mathrm{E}$ & Espontaneísta & Construtivista & $\operatorname{Sim}$ \\
\hline A & Alternativo & Construtivista & $\operatorname{Sim}$ \\
\hline $\mathrm{TC}$ & Tradicional-Tecnológico & Tradicional & $\operatorname{Sim}$ \\
\hline TE & Tradicional-Espontaneísta & Indefinida & Não \\
\hline TA & Tradicional-Alternativo & Indefinida & Não \\
\hline $\mathrm{CE}$ & Tecnológico-Espontaneísta & Indefinida & Não \\
\hline $\mathrm{CA}$ & Tecnológico-Alternativo & Indefinida & Não \\
\hline EA & Espontaneísta-Alternativo & Construtivista & $\operatorname{Sim}$ \\
\hline TCA & $\begin{array}{l}\text { Tradicional-Tecnológico- } \\
\text { Alternativo }\end{array}$ & $\begin{array}{l}\text { Indefinida com maior } \\
\text { tendência para tradicional }\end{array}$ & Não \\
\hline TEA & $\begin{array}{l}\text { Tradicional-Espontaneísta- } \\
\text { Alternativo }\end{array}$ & $\begin{array}{l}\text { Indefinida com } \\
\text { maior tendência para } \\
\text { construtivista }\end{array}$ & Não \\
\hline CEA & $\begin{array}{l}\text { Tecnológico-Espontaneísta- } \\
\text { Alternativo }\end{array}$ & $\begin{array}{l}\text { Indefinida com maior } \\
\text { tendência para tradicional }\end{array}$ & Não \\
\hline TCEA & $\begin{array}{l}\text { Tradicional/Tecnológico- } \\
\text { Espontaneísta/Alternativo }\end{array}$ & Indefinida & Não \\
\hline
\end{tabular}

Fonte: Santos Jr. e Marcondes (2010).

\section{Representações acerca do "fazer pedagógico"}

Para compreender como as disciplinas pedagógicas podem ter tido influência nas declarações dadas pelos licenciandos é importante que se apresente a organização básica do curso de química em que os participantes estão vinculados.

O curso é dividido em dez semestres e, para fins de explanação nesse trabalho, foram divididas em duas categorias: as científicas (cuja natureza diz respeito aos conhecimentos químicos) e as didático-pedagógicas (que se relacionam com a docência). A organização das disciplinas é apresentada na Figura 1. Cabe informar que o estágio supervisionado é distribuído da seguinte maneira: no $7^{\circ}$ semestre o estudante cursa 4 créditos e, nos restantes $8^{\circ}, 9^{\circ}$ e $10^{\circ}$ semestres, o estudante cursa 10 créditos em cada caso. Como se nota na Figura 1 , o $7^{\circ}$ semestre aumenta a relação entre as disciplinas pedagógicas e específicas. 
Santos Junior, J. B.; Silva, F. K. M.

Figura 1. Gráfico com a distribuição das disciplinas do curso

Distribuição das disciplinas do curso de Química em \%

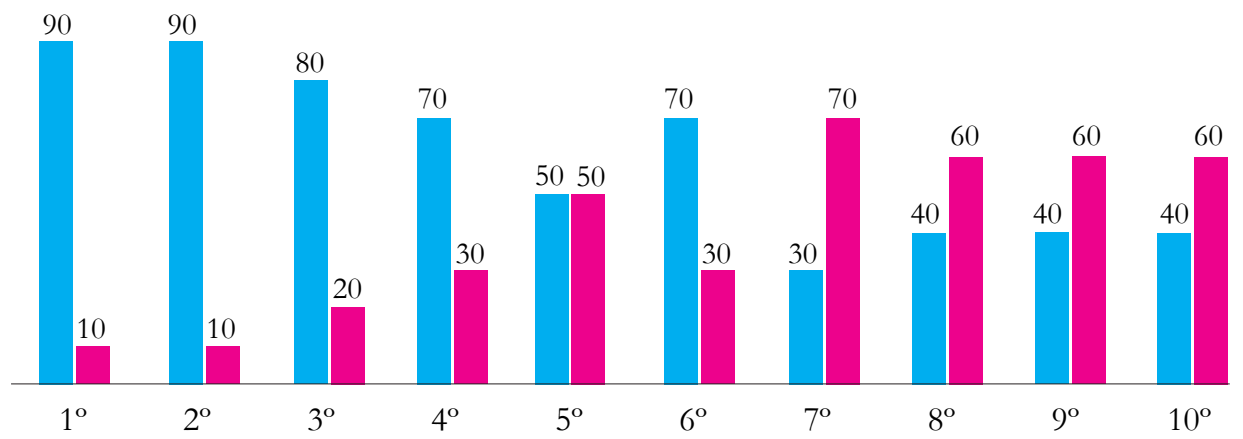

semestre semestre semestre semestre semestre semestre semestre semestre semestre semestre

disciplinas específicas

disciplinas didático-pedagógicas

Fonte: elaborado pelos autores a partir dos dados da pesquisa.

Os resultados obtidos a partir da organização dos dados coletados foram sistematizados no Quadro 4. As células em destaque correspondem às características aceitas pelos licenciandos para cada uma das cinco dimensões didáticas analisadas.

Quadro 4. Modelos didáticos identificados a partir das declarações no instrumento

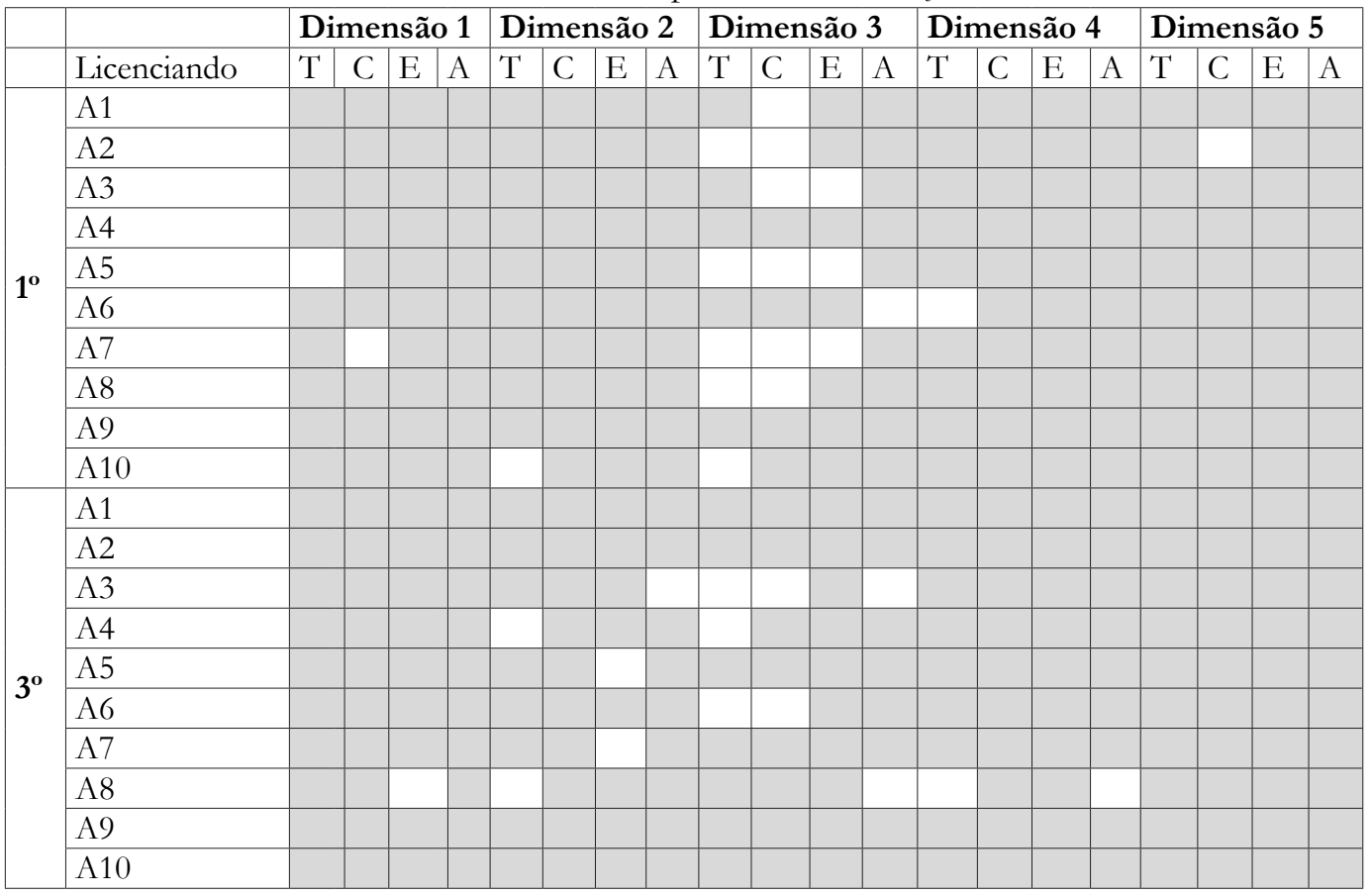

continua 
Quadro 4. continuação

\begin{tabular}{|c|c|c|c|c|c|c|c|c|c|c|c|c|c|c|c|c|c|c|c|c|c|}
\hline & & \multicolumn{4}{|c|}{ Dimensão 1} & \multicolumn{4}{|c|}{ Dimensão 2} & \multicolumn{4}{|c|}{ Dimensão 3} & \multicolumn{4}{|c|}{ Dimensão 4} & \multicolumn{4}{|c|}{ Dimensão 5} \\
\hline \multirow{11}{*}{$5^{\circ}$} & Licenciando & $\mathrm{T}$ & C & $E$ & A & $\mathrm{T}$ & $\mathrm{C}$ & $\mathrm{E}$ & A & $\mathrm{T}$ & C & $E$ & A & $\mathrm{T}$ & C & E & A & $\mathrm{T}$ & C & $E$ & A \\
\hline & A1 & & & & & & & & & & & & & & & & & & & & \\
\hline & A2 & & & & & & & & & & & & & & & & & & & & \\
\hline & A3 & & & & & & & & & & & & & & & & & & & & \\
\hline & A4 & & & & & & & & & & & & & & & & & & & & \\
\hline & A5 & & & & & & & & & & & & & & & & & & & & \\
\hline & A6 & & & & & & & & & & & & & & & & & & & & \\
\hline & A7 & & & & & & & & & & & & & & & & & & & & \\
\hline & A8 & & & & & & & & & & & & & & & & & & & & \\
\hline & A9 & & & & & & & & & & & & & & & & & & & & \\
\hline & A10 & & & & & & & & & & & & & & & & & & & & \\
\hline \multirow{13}{*}{$7^{\circ}$} & A1 & & & & & & & & & & & & & & & & & & & & \\
\hline & A2 & & & & & & & & & & & & & & & & & & & & \\
\hline & A3 & & & & & & & & & & & & & & & & & & & & \\
\hline & A4 & & & & & & & & & & & & & & & & & & & & \\
\hline & A5 & & & & & & & & & & & & & & & & & & & & \\
\hline & A6 & & & & & & & & & & & & & & & & & & & & \\
\hline & A7 & & & & & & & & & & & & & & & & & & & & \\
\hline & A8 & & & & & & & & & & & & & & & & & & & & \\
\hline & A9 & & & & & & & & & & & & & & & & & & & & \\
\hline & A10 & & & & & & & & & & & & & & & & & & & & \\
\hline & A11 & & & & & & & & & & & & & & & & & & & & \\
\hline & A12 & & & & & & & & & & & & & & & & & & & & \\
\hline & A13 & & & & & & & & & & & & & & & & & & & & \\
\hline \multirow{10}{*}{$9^{\circ}$} & A1 & & & & & & & & & & & & & & & & & & & & \\
\hline & A2 & & & & & & & & & & & & & & & & & & & & \\
\hline & A3 & & & & & & & & & & & & & & & & & & & & \\
\hline & A4 & & & & & & & & & & & & & & & & & & & & \\
\hline & A5 & & & & & & & & & & & & & & & & & & & & \\
\hline & A6 & & & & & & & & & & & & & & & & & & & & \\
\hline & A7 & & & & & & & & & & & & & & & & & & & & \\
\hline & A8 & & & & & & & & & & & & & & & & & & & & \\
\hline & A9 & & & & & & & & & & & & & & & & & & & & \\
\hline & A10 & & & & & & & & & & & & & & & & & & & & \\
\hline
\end{tabular}

Fonte: elaborado pelos autores a partir dos dados da pesquisa.

Os resultados obtidos com os licenciandos do $1^{\circ}$ e $3^{\circ}$ semestres apontam que os alunos não percebem as diferenças entre as características que compõem os modelos didáticos que declararam valorizar. Chamou a atenção o número de modelos híbridos compostos por características de três ou mais dos modelos básicos. Em todas as dimensões didáticas analisadas foram encontrados o híbrido do tipo TCEA que aponta para a ausência de um modelo didático representativo e que se caracteriza pelo alto grau de inconsistência entre as suas características. A análise dos resultados mostra que todas as dimensões didáticas são problemáticas para os dois grupos, embora na dimensão que tratava da relevância das ideias e interesses dos alunos no ensino tenha sido detectada uma discreta melhora, isto é, uma inconsistência menor. 
Uma consulta às informações apresentadas na Figura 1 permite inferir que, no caso desses licenciandos, a carência de disciplinas pedagógicas seja um fator responsável pela aparente inconsistência. Essa carência se traduz em falta de conhecimentos sobre a complexidade da atividade docente. É observado que até o final do $2^{\circ}$ semestre a carga horária destinada às disciplinas de natureza didático-pedagógica corresponde a 10\% do total de créditos cumpridos. Esse cenário é modificado no $3^{\circ}$ semestre, em que o total de créditos é ampliado para $20 \%$. Nesse sentido, pode-se inferir que tais resultados podem ter relação direta com a falta de conhecimentos por parte dos licenciandos.

Para o grupo formado pelos licenciandos que cursavam o $5^{\circ}$ semestre é observada uma discreta evolução na organização do pensamento docente. Isso se evidenciou ao se focalizarem os modelos didáticos identificados na dimensão 3. A maioria dos alunos refutou as características dos modelos didáticos tradicional e tecnológico que eram alinhados à ideia simplória de transmissão. Em contrapartida as características do modelo espontaneísta compunham praticamente os modelos didáticos pessoais dos licenciandos dentro dessa dimensão. De fato, pode-se identificar que o híbrido do tipo EA que se caracteriza por ter consistência e a mesma orientação pedagógica, foi identificado para três licenciandos. Dois alunos declararam aceitar exclusivamente as características do modelo alternativo. Dessa forma, fica evidente que para essa dimensão metade do grupo consegue diferenciar as características apresentadas e estabelecer uma tendência. O modelo didático híbrido do tipo CEA composto por elementos dos modelos tecnológico/espontaneísta/alternativo que apresenta inconsistências foi identificado para três licenciados, contudo, esse híbrido contém elementos alinhados ao construtivismo. Dentro dessa perspectiva, é possível inferir que para a maioria dos licenciandos do $5^{\circ}$ semestre para a dimensão 3 , a tendência ao alinhamento para o construtivismo foi confirmada. Sobre as demais dimensões pode-se identificar que o refutamento às características do modelo tradicional pode ser, ainda que de maneira discreta, observada em alguns alunos, mas, ainda muito distante do que foi observado para a dimensão 3 .

A organização do curso no $5^{\circ}$ semestre apresenta $50 \%$ do total de créditos dedicados para as disciplinas de natureza didático-pedagógica e esse fato indica relação direta com a evolução observada nos modelos didáticos dos licenciandos.

A análise dos modelos didáticos identificados nos licenciandos que cursavam o $7^{\circ}$ semestre aponta para ideias melhor organizadas em algumas de as dimensões didáticas analisadas em relação aos grupos anteriores. Contudo, pode-se observar que nas dimensões 1, 2 e 5 que tratavam dos objetivos do ensino, da seleção de conteúdos e da avaliação respectivamente, se concentravam muitos modelos híbridos inconsistentes. Para a dimensão 4 que focalizava a metodologia do ensino, foi constatada uma discreta evolução em relação aos modelos das dimensões 1 e 2. É possível que os professores responsáveis pelas disciplinas didático-pedagógicas tenham até essa fase do curso enfatizado aspectos metodológicos em suas aulas e abordado menos questões vinculadas à filosofia da Educação. A dimensão 3 mostrou-se, mais uma vez, ser a menos problemática para os licenciandos.

$\mathrm{O} 7^{\circ}$ semestre apresenta um momento importante no curso de Química, pois é a partir de então que os alunos começam a ter maior carga horária de disciplinas didático-pedagógicas em relação às específicas. Cabe reforçar que é nesse semestre que os alunos iniciam os estágios supervisionados. Nesse caso, assuntos relacionados ao exercício da docência e à sala de aula ganham maior peso na rotina dos alunos favorecendo o incremento de discussões sobre essa 
temática e propiciando maior reflexão. Dessa forma, faz sentido que esses licenciandos apresentem modelos didáticos mais consistentes que os licenciandos que cursavam semestres anteriores.

Para esse período, os estudantes tendem a apresentar um distanciamento de alusões à categoria "tradicional", notadamente nas dimensões 3, 4 e 5. Mas isso não é tão substancial, considerando os dados dos licenciandos do $9^{\circ}$ semestre. É verdade que se se verificou uma evolução em relação ao grupo anterior. Por exemplo, para esse grupo observou-se que nas dimensões 1, 2 e 4 que abordavam os objetivos do ensino, da seleção de conteúdos e da metodologia do ensino apresentaram menor incidência de modelos híbridos inconsistentes quando comparado aos outros grupos. A dimensão 5 que abordava a avaliação, mostrou-se a mais problemática para esses licenciandos. Nesse sentido alguns trabalhos apontam que a avaliação é um tema que abrange múltiplas interfaces e tal complexidade apresenta alto grau de dificuldade para os licenciandos (ESTEBAN, 2004). Chamou a atenção o surgimento do híbrido do tipo CE composto por características dos modelos didáticos tecnológico/espontaneísta e de organização inconsistente e que até o momento, não havia sido detectado. Tal híbrido foi identificado nas respostas de cinco licenciandos e podem ter relação direta com o fato que alguns dos licenciandos fizeram ou estavam fazendo seus estágios em escolas particulares de uma rede conhecida e propagam que suas instalações modernas e os materiais de apoio fazem a diferença na aprendizagem dos estudantes. Vale reforçar que o modelo tecnológico se fundamenta na inclusão de temáticas atuais e processos pedagógicos mais tecnológicos, mas, pode centrar-se na transmissão cultural e com foco no professor. Uma investigação mais detida e detalhada poderia apontar com mais ênfase se os licenciandos refletem ou não acerca das limitações desse modelo didático.

Mais uma vez, a organização do curso parece ter relação direta com o maior grau de consistência com os modelos didáticos apresentados por esse grupo de alunos, pois no momento em que responderam ao instrumento os licenciandos já estavam há mais tempo envolvidos com as disciplinas de natureza didático-pedagógica. Neste caso, já haviam cumprido os estágios supervisionados I e II e começado o III, portanto, nesse período o grupo já havia estabelecido contato direto com a escola e com professores em exercício. Somando-se a isso, o trabalho junto aos docentes da universidade também já se voltava para o aprofundamento da reflexão sobre o processo pedagógico e sobre o ensino.

Para efeito de comparação sobre as diferenças dos modelos didáticos identificados a partir das respostas dos licenciandos é apresentado na Figura 2 um comparativo entre esses modelos de acordo com o seu grau de consistência. Observa-se que à medida que os licenciandos vivenciam maior contato com as disciplinas de natureza didático-pedagógica vão gradativamente organizando suas ideias sobre o ensino e apresentando modelos didáticos mais consistentes. Comparando-se os modelos didáticos identificados com os licenciandos com os identificados em outro estudo com professores de química em exercício na rede pública de São Paulo (SANTOS JR.; MARCONDES, 2010), verifica-se que são semelhantes. Tal fato permite fazer duas inferências extremamente importantes no contexto da formação docente. Primeiro: que apenas o exercício da docência por si não favorece a reestruturação do pensamento docente e, segundo, que esse processo de reestruturação pode levar muito tempo. Em ambos os casos, a solução parece ser a mesma, é preciso potencializar os espaços existentes que favoreçam a reflexão sobre as ideias e concepções sobre o ensino-aprendizagem, tanto na formação inicial como na continuada. Nesse sentido, para o caso da formação inicial: introduzir discussões mais promissoras e concretas, para o caso da formação continuada, explorar espaços coletivos, 
tentando aprimorar e construir junto aos professores uma formação dedicada a compreender a prática docente e suas demandas.

Figura 2. Gráfico comparativo com os modelos didáticos dos licenciandos

Modelos didáticos identificados nas declarações dos licenciandos

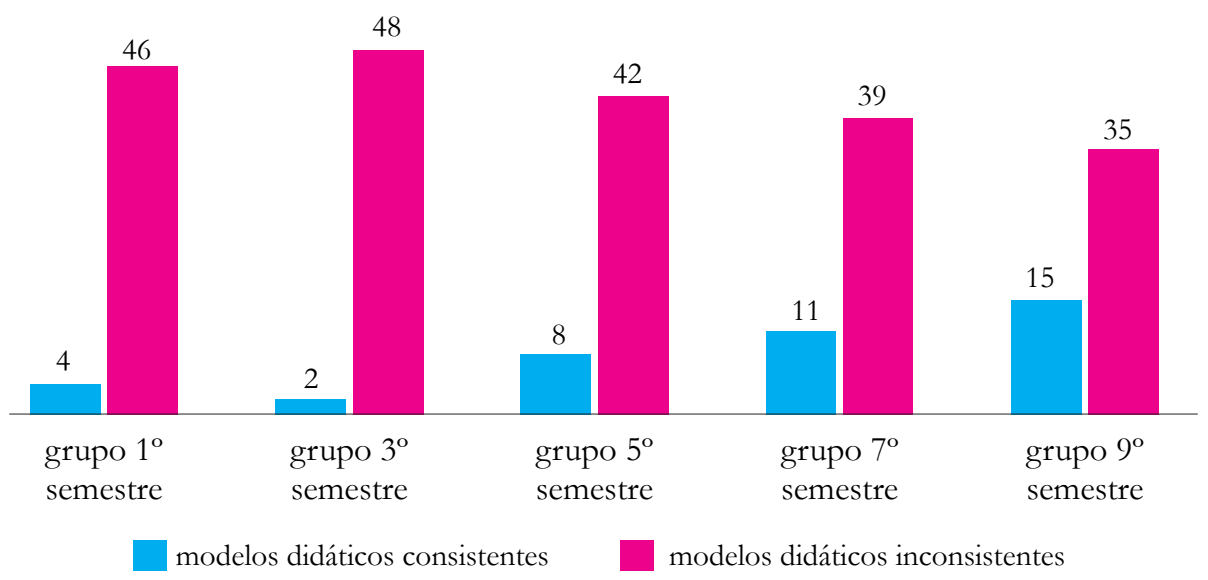

Fonte: elaborado pelos autores a partir dos dados da pesquisa.

\section{Conclusões}

Os resultados aqui obtidos corroboram com aqueles apresentados por Pinto Neto, Queiroz e Zanon (2009) e Ferreira e Frota (2004) sobre como as disciplinas pedagógicas favorecem a evolução das ideias e das concepções dos futuros professores sobre a atividade docente. Nesse sentido, apesar dos numerosos desafios enfrentados pelas Instituições de Ensino Superior (IES) no que concerne à formação dos licenciandos, é preciso ampliar o engajamento dos formadores visando a proposição de currículos mais alinhados com as demandas requeridas para o exercício da atividade docente. Não se trata de valorizar as disciplinas de natureza pedagógica em detrimento das disciplinas de natureza específica e, sim, de romper com tal dicotomia e reconhecer ambas como importantes na formação do futuro professor e por isso podem ser abordadas de maneira articulada pelos docentes. Nesse caso, é importante partir do ideário de que o currículo destinado à formação do professor é (ou deveria ser) material em permanente construção. É sempre oportuno refletir sobre a formação docente, em especial, no atual momento em que as IES estão debatendo sobre as possíveis adequações que deverão ser implementadas nas licenciaturas para fins de adequação às diretrizes para a formação de professores. 
Análise dos modelos didáticos pessoais ...

\section{Referências}

ABIB, M. L. V. S. A contribuição da prática de ensino na formação inicial de professores de física. In: ROSA, D. E. G.; SOUZA, V. C. Didáticas e práticas de ensino: interfaces com diferentes saberes e lugares formativos. Rio de Janeiro: DP\&A, 2002. p. 188-204.

ANDRÉ, M. E. D. A. A produção acadêmica sobre formação docente: um estudo comparativo das dissertações e teses dos anos 1990 e 2000. Revista Brasileira de Pesquisa sobre Formação de Professores, Belo Horizonte, v. 1, n. 1, p. 41-56, ago./dez. 2009.

BRASIL. Conselho Nacional de Educação. Resolução no 2, de $1^{\circ}$ de julho de 2015. Define as diretrizes curriculares nacionais para a formação inicial em nível superior (cursos de licenciatura, cursos de formação pedagógica para graduados e cursos de segunda licenciatura) e para a formação continuada. Diário Oficial [da] República Federativa do Brasil, Brasília, n. 124, p. 8-12, 02 jul. 2015. Seção. Disponível em: < http://pronacampo.mec.gov. br/images/pdf/res_cne_cp_02_03072015.pdf >. Acesso em: 13 abr. 2017.

CHROBAK, R.; BENEGAS, M. L. Mapas conceptuales y modelos didacticos de professores de química. In: CAÑAS, A. J.; NOVAK, J. D. (Ed.). Concept maps: theory, methodology, technology: proceedings of the second international conference on concept mapping. San José, 2006. Disponível em: <http://cmc.ihmc.us/cmc2006Papers/cmc2006-p215.pdf>. Acesso em: 24 out. 2016.

DOURADO, L. F. Diretrizes curriculares nacionais para a formação inicial e continuada dos profissionais do magistério da educação básica: concepções e desafios. Educação \& Sociedade, Campinas, v. 36, n. 131, p. 299-324, abr.-jun., 2015. Disponível em: <http:// dx.doi.org/10.1590/ES0101-73302015151909>. Acesso em: 13 abr. 2017.

ESTEBAN, M. T. A avaliação no cotidiano escolar. In: (Org.). Avaliação: uma prática em busca de novos sentidos. Rio de Janeiro: DP\&A, 2004. p. 7-28.

FERREIRA, L. H. B.; FROTA, P. R. O. Contribuição das disciplinas pedagógicas para a formação conceitual dos licenciandos em ciências da UFPI. In: ENCONTRO DE PESQUISA EM EDUCAÇÃO DA UFPI, 3., 2004. Disponível em: < http://leg.ufpi.br/ subsiteFiles/ppged/arquivos/files/eventos/evento2004/GT.2/GT2_11_2004.pdf>. Acesso em: 24 out. 2016.

GARCÍA PÉREZ, F. F. Los modelos didácticos como instrumento de análisis y de intervención en la realidad educativa. Biblio 3W: revista bibliográfica de geografía y ciencias sociales, Barcelona, n. 207, feb. 2000. Disponível em: <http://www.ub.es/geocrit/b3w-207. htm>. Acesso em: 24 out. 2016.

GIL-PÉREZ, D.; CARVALHO, A. M. P. Formação de professores de ciências. São Paulo: Cortez, 1992.

GRIGOLI, J. A. G. et al. A escola como lócus de formação docente: uma gestão bemsucedida. Cadernos de Pesquisa, São Paulo, v. 40, n. 139, p. 237-256, 2010. Disponível em: <http://dx.doi.org/10.1590/S0100-15742010000100012>. Acesso em: 24 out. 2016. 
GUIMARÃES, M. A. G.; ECHEVERRÍA, A. R.; MORAES, J. I. Modelos didáticos no discurso de professores de ciências. Revista Eletrônica de Investigação em Ensino de Ciências, Porto Alegre, v. 11, n. 3, p. 303-322, 2006. Disponível em: < http:/ /www.if.ufrgs. br/ienci/artigos/Artigo_ID155/v11_n3_a2006.pdf>. Acesso em: 24 out. 2016

MIZUKAMI, M. D. G. N. et al. Escola e aprendizagem da docência: processos de investigação e formação. São Carlos: EdUFSCar, 2002.

PAGANINI, E. L. Superando (in)seguranças no início de carreira docente. In: SEMINÁRIO DE PESQUISA EM EDUCAÇÃO DA REGIÃO SUL, 9., 2012. Disponível em: <http:// www.ucs.br/etc/conferencias/index.php/anpedsul/9anpedsul/paper/viewFile/208/487>. Acesso em: 24 out. 2016.

PINTO NETO, P. C.; QUEIROZ, S. L.; ZANON, D. A. V. As disciplinas pedagógicas na formação e na construção de representações sobre o trabalho docente: visões de alunos de licenciatura em química e física. Educar, Curitiba, n. 34, p. 75-94, 2009. Disponível em: <http://www.scielo.br/pdf/er/n34/05.pdf>. Acesso em: 24 out. 2016.

PORLÁN ARIZA, R.; RIVERO GARCÍA, A.; MARTÍN DEL POZO, R. Conocimiento profesional y epistemología de los profesores I: teoría, métodos e instrumentos. Enseñanza de las Ciencias, Barcelona, v. 15, n. 2, p. 155-171, 1997. Disponível em: <http://www.raco. cat/index.php/ensenanza/article/viewFile/21488/93522>. Acesso em: 24 out. 2016.

PORLÁN ARIZA, R.; RIVERO GARCÍA, A.; MARTÍN DEL POZO, R. Conocimiento profesional y epistemología de los profesores II: estudios empíricos y conclusiones.

Enseñanza de las Ciencias, Barcelona, v. 16, n. 2, p. 271-288, 1998.

RAYMUNDO, G. M. C. O estágio supervisionado: lócus formativo para acadêmicos que atuam como professores na educação básica. In: SEMINÁRIO DE PESQUISA EM EDUCAÇÃO DA REGIÃO SUL, 10., 2014, Florianópolis. Anais... Florianópolis: UDESC, 2014. Disponível em: <http://xanpedsul.faed.udesc.br/arq_pdf/1112-0.pdf>. Acesso em: 18 abr. 2017.

SANT’ANNA, N. F. P.; MATTOS, F. R. P.; COSTA, C. S. Formação continuada de professores: a experiência do programa de residência docente no colégio Pedro II.

Educação em Revista, Belo Horizonte, v. 31, n. 4, p. 249-278, 2015. Disponível em: <http:/ /www.scielo.br/pdf/edur/v31n4/1982-6621-edur-31-04-00249.pdf>. Acesso em: 24 out. 2016

SANTOS JR., J. B.; MARCONDES, M. E. R. Identificando os modelos didáticos de um grupo de professores de química. Ensaio, Belo Horizonte, v. 12, n. 3, p. 101-116, 2010. Disponível em: <http://www.portal.fae.ufmg.br/seer/index.php/ensaio/article/ view/525/517>. Acesso em: 22 out. 2016.

Artigo recebido em 20/06/2016. Aceito em 02/11/2016.

Endereço para contato: Universidade Federal de São Carlos, DFQM, Rodovia João Leme dos Santos (SP-264), Km. 110, Sorocaba, 18052780, SP, Brasil. 